
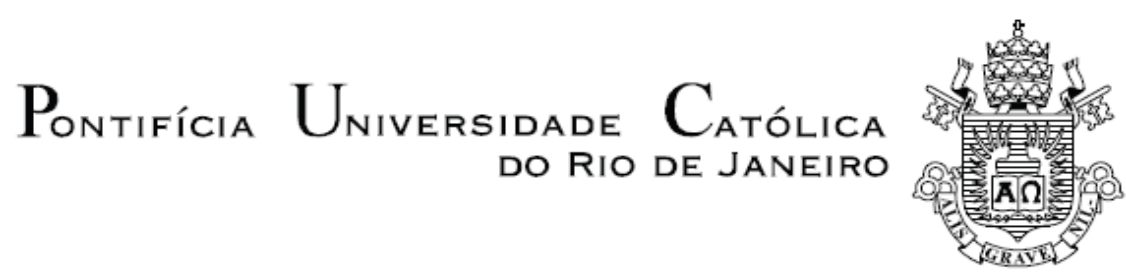

Felippe Borges Costa

Valoração da Flexibilidade de uma Sonda Dedicada em uma Plataforma de Petróleo: Uma Abordagem via Opções Reais

Dissertação de Mestrado

Dissertação apresentada como requisito parcial para obtenção do título de Mestre pelo Programa de PósGraduação em Engenharia Elétrica da PUC-Rio.

Orientador: Reinaldo Castro Souza Co-Orientador: Marco Antonio Guimarães Dias 

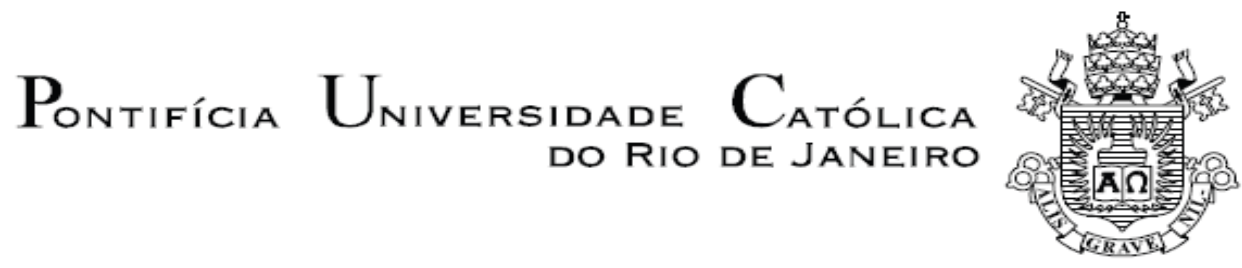

Felippe Borges Costa

\title{
Valoração da Flexibilidade de uma Sonda Dedicada em uma Plataforma de Petróleo: Uma Abordagem via Opções Reais
}

\begin{abstract}
Dissertação apresentada como requisito parcial para obtenção do título de Mestre pelo Programa de PósGraduação em Engenharia Elétrica do Departamento de Engenharia Elétrica do Centro Técnico Científico da PUCRio. Aprovada pela Comissão Examinadora abaixo assinada.
\end{abstract}

\author{
Reinaldo Castro Souza \\ Orientador \\ Departamento de Engenharia Elétrica - PUC-Rio \\ Marco Antonio Guimarães Dias \\ Co-orientador \\ Departamento de Engenharia Industrial - PUC-Rio \\ Carlos Patrício Samanez \\ Departamento de Engenharia Industrial - PUC-Rio \\ Juan Guillermo Lazo Lazo \\ Departamento de Engenharia Industrial - PUC-Rio \\ José Eugênio Leal \\ Coordenador Setorial do Centro Técnico Científico - PUC-Rio
}

Rio de Janeiro, 27 de julho de 2010 
Todos os direitos reservados. É proibida a reprodução total ou parcial do trabalho sem autorização da universidade, do autor e do orientador.

\section{Felippe Borges Costa}

Graduou-se em Economia na Universidade Federal de Juiz de Fora em 2007. Trabalha desde 2009 na Petrobras na área de análise econômica de projetos.

Ficha Catalográfica

Costa, Felippe Borges

Valoração da flexibilidade de uma sonda dedicada em uma plataforma de petróleo: uma abordagem via opções reais / Felippe Borges Costa; orientador: Reinaldo Castro Souza; co-orientador: Marco Antônio Guimarães Dias. 2010.

99 f.: il. (color.) ; $30 \mathrm{~cm}$

Dissertação (Mestrado em Engenharia Elétrica) Pontifícia Universidade Católica do Rio de Janeiro, 2010. Inclui bibliografia

1. Engenharia Elétrica - Teses. 2. Opções Reais. 3. Petróleo. 4. Completação molhada e seca. 5. Intervenção em poço. I. Souza, Reinaldo Castro. II. Dias, Marco Antonio Guimarães. III. Pontifícia Universidade Católica do Rio de Janeiro. Departamento de Engenharia Elétrica. IV. Título.

CDD: 621.3 


\section{Agradecimentos}

Aos meus pais, Cleber e Fátima, pela educação, incentivo e oportunidades que sempre me proporcionaram.

Ao meu irmão, Diego, pela amizade e compreensão.

A todos os meus familiares pelo carinho e apoio.

À minha namorada, Ana Carolina, pelo incentivo e companheirismo.

Aos meus amigos e colegas pelo apoio e compreensão.

Aos meus colegas da Petrobras pelas sugestões e discussões.

Ao meu orientador, Reinaldo, pela confiança e oportunidade de realizar o mestrado.

Ao meu co-orientador, Marco Antônio, pelos valiosos ensinamentos, oportunidades e apoio.

A todos os professores e funcionários do Departamento de Engenharia Elétrica da PUC-Rio, pelos ensinamentos e apoio.

À Capes e à PUC-Rio pelo apoio financeiro e oportunidade de formação. 


\section{Resumo}

Costa, Felippe Borges; Souza, Reinaldo Castro. Valoração da Flexibilidade de uma Sonda Dedicada em uma Plataforma de Petróleo: Uma Abordagem via Opções Reais. Rio de Janeiro, 2010. 99p. Dissertação de Mestrado - Departamento de Engenharia Elétrica, Pontifícia Universidade Católica do Rio de Janeiro.

Diversos problemas operacionais ou falhas podem ocorrer em poços produtores e injetores em campos de petróleo e reduzir a produção. Muitas vezes a solução para esse tipo de problema é a intervenção com sonda. No caso de a plataforma de petróleo possuir uma sonda própria de intervenção, essa operação se torna mais ágil e menos dispendiosa. Apesar de proporcionar maior flexibilidade através do gerenciamento ativo da produção, a existência de uma sonda de intervenção acoplada à plataforma geralmente aumenta o investimento requerido em comparação à alternativa sem sonda dedicada. O objetivo desta dissertação foi o de apresentar uma proposta de metodologia, baseada na teoria de opções reais, para a quantificação dessa flexibilidade. A metodologia foi aplicada a um estudo de caso hipotético na área do pré-sal, no qual foram analisadas as opções de intervenção nos poços produtores. A metodologia proposta foi capaz de quantificar o ganho proporcionado pela sonda dedicada. A probabilidade de ocorrência de falhas, o tempo de espera pela sonda, o tipo de falha e a duração da intervenção foram fatores que impactaram o valor da flexibilidade.

\section{Palavras-chave}

Opções reais, petróleo, completação seca, sonda dedicada, intervenção em poços, garantia de escoamento. 


\section{Abstract}

Costa, Felippe Borges; Souza, Reinaldo Castro (Advisor). Valuation of the Flexibility of a Dedicated Rig into an Oil Platform: A Real Options Approach. Rio de Janeiro, 2010. 99p. MSc. Dissertation - Departamento de Engenharia Elétrica, Pontifícia Universidade Católica do Rio de Janeiro.

Several operational problems or failures may occur in producers and injectors wells on oil fields and reduce the production. Often the solution to this problem is the well intervention with a drillship. If the production platform itself has an intervention rig, this operation becomes more agile and less costly. Despite providing greater flexibility through the active management of production, the existence of an intervention rig attached to the platform usually increases the required investment compared to alternative without a dedicated rig. The objective of this dissertation was to propose a methodology, based on real options theory, to quantify this flexibility. The methodology was applied to a hypothetical case study in the pre-salt area in which was analyzed the options for intervention in producing wells. The proposed methodology was able to quantify the improvement provided by a dedicated rig. The probability of failure, the waiting time for the drillship, the failure type and duration of the intervention were factors that impacted the value of flexibility.

\section{Keywords}

Real options, oil, dry completion, dedicated rig, well intervention, flow assurance. 


\section{Sumário}

1 Introdução

11

2 Teoria das Opções Reais 15

2.1. Introdução à Teoria das Opções Reais 15

2.2. Processos Estocásticos 28

2.2.1. Movimento Geométrico Browniano 29

2.2.2. Movimento de Reversão à Média 31

2.2.3. Processo de Poisson 35

2.3. Métodos de Cálculo das Opções Reais 37

2.3.1. Simulação de Monte Carlo 38

3 Sonda Dedicada e o Ganho de Flexibilidade 44

3.1. Introdução 44

3.2. Intervenções em Poços com Sonda de Intervenção 50

3.3. Revisão da Literatura 55

3.4. Ganho de Flexibilidade no Pré-Sal 65

4 Metodologia Proposta $\quad 69$

4.1. Introdução $\quad 69$

4.2. Incertezas de Mercado 72

4.3. Incertezas Técnicas $\quad 74$

5 Aplicação da Metodologia $\quad 77$

5.1. Introdução 77

5.2. Estudo de Caso 81

6 Conclusões 92

7 Referências Bibliográficas $\quad 95$ 


\section{Lista de figuras}

Figura 1 - Exemplo de Curva de Gatilho 20

Figura 2 - Efeito da Convexidade no Valor das Opções Reais 24

Figura 3 - Opções Reais em Petróleo 27

Figura 4 - Movimento Geométrico Browniano 30

Figura 5 - Movimento de Reversão à Média: Preço Inicial

Maior que o Preço de Longo Prazo 33

Figura 6 - Movimento de Reversão à Média: Preço Inicial

Menor que o Preço de Longo Prazo 34

Figura 7 - Sistema de Produção com FPSO 45

Figura 8 - SPAR com Acesso Vertical Direto aos Poços 46

Figura 9 - Sistema de Produção Baseado em Completação Seca 47

Figura 10 - Esquema de um Poço Produtor Equipado com Gas Lift 48

Figura 11 - Exemplo de uma Linha Obstruída por Depósito de Parafina 51

Figura 12 - Número de Poços Produtores e de Intervenções 63

Figura 13 - Principais Causas de Intervenções em Poços 63

Figura 14 - Duração Total das Intervenções por Motivo 64

Figura 15 - Recordes de Profundidade de Perfuração de Poços 65

Figura 16 - Evolução Histórica do Óleo Brent e da Taxa de Sonda 72

Figura 17 - Exemplo do Impacto de uma Incrustação

na Produção de um Poço $\quad 75$

Figura 18 - Curva de Produção Total Potencial 78

Figura 19 - Curvas de Produção de uma Iteração para

a Alternativa Completação Molhada $\quad 84$

Figura 20 - Curvas de Produção de uma Iteração para

a Alternativa Completação Seca 84

Figura 21 - Distribuição do VPL da Alternativa Completação Seca

para o Caso Base $\quad 85$

Figura 22 - Distribuição do VPL da Alternativa Completação Seca

para o Caso Base $\quad 85$

Figura 23 - Distribuição do Total de Falhas dos Poços para o Caso Base 86 


\section{Lista de tabelas}

Tabela 1 - Analogia entre a Opção Financeira de Compra

e a Opção Real de Desenvolver um Campo de Petróleo 22

Tabela 2 - Impacto das Variáveis no Valor do Gatilho e da Opção Real 23

Tabela 3 - Prós e Contras das Unidades Dotadas

de Sonda Própria para o Pré-sal 66

Tabela 4 - Fluxo de Caixa Adotado na Análise 71

Tabela 5 - Cronograma e Pico de Produção dos Poços Produtores 78

Tabela 6 - Premissas Gerais do Estudo de Caso 79

Tabela 7 - Probabilidade de Ocorrência de Falha nos Poços Produtores

de Acordo com o Parâmetro de Escala da Distribuição de Weibull 82

Tabela 8 - Premissas para o Caso Base $\quad 82$

Tabela 9 - Resultado da Simulação para o Caso Base 83

Tabela 10 - Impacto da Probabilidade de Ocorrência

de Falhas dos Poços Produtores no Valor da Flexibilidade 87

Tabela 11 - Impacto do Tempo de Espera pela Sonda

no Valor da Flexibilidade $\quad 88$

Tabela 12 - Impacto da Duração da Intervenção no Valor da Flexibilidade 89

Tabela 13 - Impacto do Tipo de Falha no Valor da Flexibilidade 90

Tabela 14 - Premissas do Modelo de Marlim 90

Tabela 15 - Impacto da Modelagem do Óleo Brent e da Taxa de Sonda

através do Modelo de Marlim no Valor da Flexibilidade 91 


\section{Lista de Siglas}

ANP - Agência Nacional do Petróleo

CAPM - capital asset pricing model (modelo de precificação de ativos de capital)

$\mathrm{E} \& \mathrm{P}$ - exploração e produção

FCD - fluxo de caixa descontado

FOB - free on board

FPDSO - floating production drilling storage and offloading

FPSO - floating production storage and offloading

MGB - movimento geométrico Browniano

MRM - movimento de reversão à média

OPEP - Organização dos Países Produtores de Petróleo

SS - semi-submersível

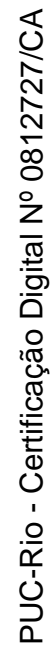

TLP - tension leg platform

TLWP - tension leg wellhead platform

VBA - Visual Basic for Applications

VPL - valor presente líquido 